\title{
FOURIER-TRANSFORM INFRARED SPECTROSCOPY STUDIES AND EVALUATION OF TOTAL PHENOLICS, FLAVONOIDS, AND ANTIOXIDANT ACTIVITY OF CLEOME GYNANDRA
}

\author{
RAMYA KUBER BANOTH*, ASHWINI THATIKONDA
}

Department of Pharmacognosy, Institute of Pharmaceutical Technology, Sri Padmavati Mahila Visvavidyalayam (Women's University), Tirupati, Andhra Pradesh, India. Email: rkuberpharma@yahoo.com

Received: February 14 2019, Revised and Accepted: April 292019

\section{ABSTRACT}

Objective: The objective of this study was to evaluate the nature of chemical constituents, total phenolics, total flavonoids, and antioxidant activity of Cleome gynandra and their functional groups with the help of phytochemical, Fourier-transform infrared spectroscopy (FTIR) analysis, colorimetric assay, and 2,2-diphenyl-1-picrylhydrazyl (DPPH) free radical scavenging assay.

Methods: C. gynandra of the Cleomaceae family is an annual herb. The dried leaves were powdered and extracted using Soxhlet apparatus by different solvents. Preliminary phytochemical analysis was carried out to identify the phytoconstituents present in the extract of $C$. gynandra, FTIR spectrum was scanned at the range of $4000-400 \mathrm{~cm}^{-1}$. The extracts were subjected to the colorimetric assay in triplicate manner to quantitative determination of total phenolic and total flavonoid content. Gallic acid and rutin used as standards to determine the total phenolic content and total flavonoid content. Antioxidant activity was evaluated using DPPH radical scavenging method.

Results: Phytochemical analysis of the ethanolic extract of $C$. gynandra revealed the presence of alkaloids, phenolics, saponins, steroids, flavonoids, cardiac glycosides, and tannins. FTIR spectrum showed intense bands at 3679.18, 3616.63, 3317.34, 2943.67, 1634.01, 1360.20, 1036.71, and $778.04 \mathrm{~cm}^{-1}$ corresponding to $\mathrm{N}-\mathrm{H}_{2}, \mathrm{O}-\mathrm{H}$ stretch, aliphatic $\mathrm{C}-\mathrm{H}$ stretch, $\mathrm{C}=\mathrm{O}, \mathrm{C}-\mathrm{H}$ benzene, $\mathrm{C}-\mathrm{O}$ stretch, and $\mathrm{C}-\mathrm{Cl}$. The total phenolic content was found to be $8.39 \pm 0.0952 \mathrm{mg}$ gallic acid equivalent/g and $66.76 \pm 0.0333 \mathrm{mg}$ rutin equivalent/g. The DPPH radical scavenging activity of ethanolic extract was showed more scavenging activity compared to ethyl acetate and n-hexane fractions.

Conclusion: The present research work creates a platform to screen many bioactive chemical constituents present in $C$. gynandra to treat various diseases.

Keywords: Cleome gynandra, Phytochemicals, Fourier-transform infrared spectroscopy, Total phenolic and flavonoid contents, 2,2-diphenyl-1picrylhydrazyl scavenging activity.

(C) 2019 The Authors. Published by Innovare Academic Sciences Pvt Ltd. This is an open access article under the CC BY license (http://creativecommons. org/licenses/by/4. 0/) DOI: http://dx.doi.org/10.22159/ajpcr.2019.v12i6.32598

\section{INTRODUCTION}

Medicinal plant plays an important role in our daily ayurvedic practices [1]. Plants are valuable source for natural treatment, so many natural products have been obtained from plants for maintaining human health. The ethnopharmacological activities are directly related to phytochemical information; it is generally considered an effective approach in the discovery of new active agents [2]. Hence, characterization of plants through a variety of antioxidant assays is of important [3].

The plant Cleome gynandra belongs to the family Cleomaceae (Capparaceae) [4]. C. gynandra is highly nutritive and it contains healthpromoting bioactive compounds important in combating malnutrition and reducing human degenerative diseases [5]. The leaves contain excessive amounts of proteins, vitamins (A and C), and minerals [6]. It is used as a vegetable in many African countries [7]. C. gynandra is a chief constituent in Narayana churna. It is widely used in several Ayurvedic medicinal formulations for its diverse medicinal properties. It contains several phytochemical constituents such as alkaloids, glycosides, carbohydrates, proteins, amino acids, polyphenols, tannins, steroids, terpenoids, and saponins. It is used in migraine, vomiting, diphtheria, vertigo, pneumonia septic ears, digestive disorders, scorpion stings, snake bites, diarrhea, insecticidal, antifeedant and repellent property, anti-tick property, anti-HIV, antibacterial activities, inhalation of the leaves relieves headaches to treat neuralgia and stiff neck, treatment of uterine complaints, antioxidant activity, anti-irritant, anthelmintic, and rubefacient [8]. The plant used in the treatment of malaria, piles, rheumatism, and tumor [9].
To promote the therapeutic compounds of medicinal plants for utilization, it is necessary to investigate their composition and activity. The functional groups present in these chemical constituents of plants are usually identified by Fourier-transform infrared (FTIR) spectroscopy. FTIR is used to elucidate the structure of isolated compounds [10]. Identification of the chemical nature of phytochemical compounds present in the medicinal plants provides some information on the different functional groups responsible for their medicinal properties [11]. Infrared spectroscopy produces a spectrum which is based on the vibrations of the atoms in molecules [12]. The phenolic compounds, which are obtained from plant parts, were showed a significant role as an antioxidant for the prevention of oxidative damage in the living organisms [13]. Polyphenols are bioactive compounds extensively spread in plants and they are significant constituents of the human diet. Plants contain a diversity of substances such as flavonoids (anthocyanins, flavonols, and flavones) as well as some classes of nonflavonoids, (phenolic stomach acids, lignins, stilbenes, terpenoids, and many others) which are responsible for antioxidant activity [14]. The ingestion of these natural antioxidants has been implicated in the reduction of risks in cancer, toxicity, inflammation, cardiovascular disease, and diabetes [15].

The aim of the present investigation deals with analysis of phytoconstituents and functional groups present in the ethanolic leaf extract of C. gynandra using FTIR spectroscopy, quantification of phenol, flavonoid content, and determination of in vitro antioxidant activity of the leaf extract of $C$. gynandra. 


\section{METHODS}

Collection of plant materials

C. gynandra plant was selected, authenticated by Dr. Madhava Chetty, Botanist, Department of Botany, Sri Venkateswara University, Tirupati. Leaves of C. gynandra were collected from Agricultural Fields, Mangalam, Tirupati, in suitable season, washed thoroughly, and dried under shade.

\section{Preparation and evaluation of ethanolic extract and its fractions of} Cleome gynandra leaves

The dried leaves were coarsely powdered, extracted exhaustively in a Soxhlet apparatus with ethanol. The ethanolic leaf extract was concentrated under reduced pressure to yield a dark green residue ( $50 \mathrm{~g} ; 6.8 \%$ yield). Fractionation of the ethanolic extract was carried out in a separating funnel using solvents of increasing polarity, n-hexane, and ethyl acetate. Ethanolic extract was suspended in distilled water and was successively partitioned with n-hexane, then with ethyl acetate to obtain n-hexane and ethyl acetate fraction.

\section{Phytochemical screening}

The ethanolic leaf extract of $C$. gynandra was subjected to various phytochemical tests to detect the presence of different phytoconstituents such as alkaloids, glycosides, carbohydrates, proteins, amino acids, polyphenols, tannins, steroids, terpenoids, and saponins [6].

\section{Fourier-transform infrared spectrum}

FTIR spectrum of the ethanolic leaf extract of $C$. gynandra was recorded in $\mathrm{KBr}$ by sophisticated computer controlled FTIR BRUKER spectrometer with He-Ne laser as reference. FTIR spectrum helps to identify the functional groups present in $C$. gynandra. The extract of C. gynandra was scanned at spectral range of $4000-400 \mathrm{~cm}^{-1}[16]$.

\section{Determination of total phenolic content}

The total phenolic content of fractions of the ethanolic leaf extract was determined using the Folin-Ciocalteu colorimetric method. The extract $(10-100 \mu \mathrm{g} / \mathrm{mL})$ or standard solution of gallic acid $(10-100 \mu \mathrm{g} / \mathrm{mL})$ was added to $25 \mathrm{~mL}$ volumetric flask containing $9 \mathrm{~mL}$ of distilled deionized water. A reagent blank was prepared using distilled water instead of sample. $1 \mathrm{~mL}$ of Folin-Ciocalteu phenol reagent was added to the mixture and shaken well. After $5 \mathrm{~min}, 10 \mathrm{~mL}$ of $7 \%$ aqueous sodium carbonate was added to the mixture. The solution was diluted to $25 \mathrm{~mL}$ with double distilled water and mixed. After incubation for $90 \mathrm{~min}$ at room temperature, the absorption against prepared reagent blank was determined at $760 \mathrm{~nm}$ using colorimeter. Quantification was done with respect to the standard gallic acid and expressed as gallic acid equivalents (GAE) in mg per gram of extract [17].

\section{Determination of total flavonoid content}

The total flavonoid content of ethanolic, n-hexane, and ethyl acetate leaf extracts was measured using the aluminum chloride colorimetric method. The extract $(10-100 \mu \mathrm{g} / \mathrm{mL})$ or standard solution of rutin $(10-100 \mu \mathrm{g} / \mathrm{ml})$ was added to $10 \mathrm{~mL}$ volumetric flask, containing $4 \mathrm{~mL}$ of double distilled water. To the flask, $0.3 \mathrm{~mL}$ of $5 \%$ sodium nitrite solution was added. After $5 \mathrm{~min}, 0.3 \mathrm{~mL}$ of $10 \%$ aluminum chloride solution was added. At the $6^{\text {th }} \mathrm{min}, 2 \mathrm{~mL}$ of $1 \mathrm{M} \mathrm{NaOH}$ was added and the total volume was made up to $10 \mathrm{~mL}$ with double distilled water. The solution mixture was mixed well and at $510 \mathrm{~nm}$, the absorbance was measured against prepared reagent blank using colorimeter. The total flavonoid content was expressed as rutin equivalents in mg per gram of extract [17].

\section{In vitro antioxidant activity}

\section{2,2-diphenyl-1-picrylhydrazyl free radical scavenging assay}

Antioxidant activity of all fractions of ethanolic leaf extract was determined using DPPH free radical scavenging activity [18]. $1 \mathrm{ml}$ of $0.1 \mathrm{mM}$ solution of DPPH in methanol was added to $2.5 \mathrm{ml}$ of the test extract in methanol $(10-100 \mu \mathrm{g} / \mathrm{ml})$. The reaction mixture was then allowed to stand for $30 \mathrm{~min}$ at room temperature in a dark place. After $30 \mathrm{~min}$, absorbance was measured at $517 \mathrm{~nm}$ using colorimeter.
Ascorbic acid was used as a standard. The scavenging activity of DPPH radical (\%) was calculated using the following equation:

$$
\% \text { Inhibition }=\left(\left[\mathrm{A}_{0}-\mathrm{A}_{1}\right] / \mathrm{A}_{0}\right) \times 100
$$

Where, $A_{0}$ - absorbance of control

$A_{1}$ - absorbance of the test sample.

\section{RESULTS}

The phytochemical analysis of the ethanolic leaf extract of C. gynandra $\mathrm{L}$. was tested by various phytochemical tests. It revealed the presence of following phytoconstituents and is shown in Table 1.

Results of FTIR spectrum analysis revealed the presence of various characteristic functional groups in ethanolic leaf extract of $C$. gynandra were obtained and depicted in Fig. 1 which confirmed the presence of functional groups, the frequency range and functional group obtained from absorption spectra are presented in Table 2.

Quantification of the total phenolic content of ethanolic leaf extract and its fractions was estimated by Folin-Ciocalteu's method using gallic

Table 1: Phytochemical evaluation of the ethanolic leaf extract of Cleome gynandra

\begin{tabular}{lll}
\hline S. No & Name of test & Result \\
\hline 1 & Alkaloids & $+\mathrm{ve}$ \\
2 & Flavonoids & $+\mathrm{ve}$ \\
3 & Tannins & $+\mathrm{ve}$ \\
4 & Terpenoids & $+\mathrm{ve}$ \\
5 & Saponins & $+\mathrm{ve}$ \\
6 & Cardiac glycosides & $+\mathrm{ve}$ \\
7 & Phenolics & $+\mathrm{ve}$ \\
8 & Anthraquinones & $-\mathrm{ve}$ \\
9 & Steroids & $+\mathrm{ve}$ \\
\hline+ ve: Present, - ve: Absent & &
\end{tabular}

Table 2: Fourier-transform infrared spectroscopy frequency range and functional groups present in the ethanolic leaf extract of Cleome gynandra

\begin{tabular}{|c|c|c|}
\hline S. No & $\begin{array}{l}\text { Frequency } \\
\text { range }\left(\mathrm{cm}^{-1}\right)\end{array}$ & Functional groups \\
\hline 1 & 3679.18 & $\mathrm{~N}-\mathrm{H}_{2}$ stretching of amines and amides \\
\hline 2 & 3616.63 & $\mathrm{O}-\mathrm{H}$ stretching vibration \\
\hline 3 & 3317.34 & $\begin{array}{l}\text { Aliphatic carboxylic acid } 0-\mathrm{H} \text { stretch } \\
\text { vibration }\end{array}$ \\
\hline 4 & 2943.67 & C-H Stretching \\
\hline 5 & 1634.01 & C-H Benzene \\
\hline 6 & 1360.20 & C-O stretch aromatic ether \\
\hline 7 & 1036.71 & $\mathrm{COH}$, alcohol \\
\hline 8 & 778.04 & Alkyl halide \\
\hline
\end{tabular}

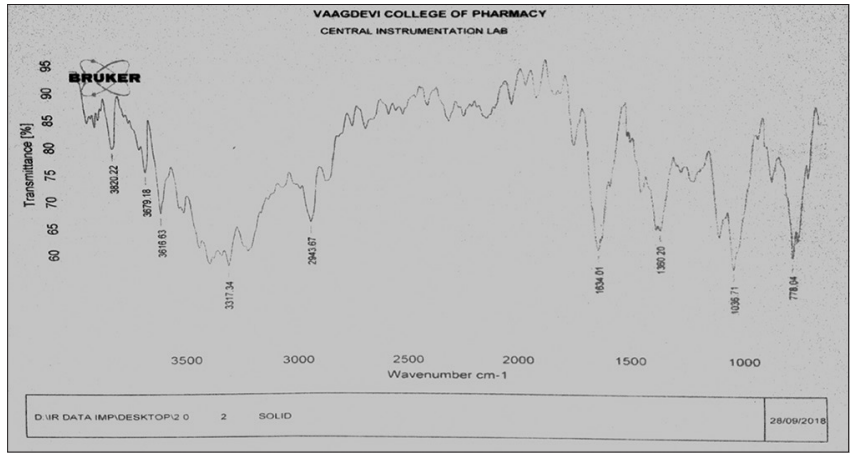

Fig. 1: Fourier-transform infrared spectroscopy spectrum of the ethanolic leaf extract of Cleome gynandra 
acid as standard. The reagent is formed after oxidation of the phenols, mixture of phosphotungstic acid and phosphomolybdic acid which after oxidation of the phenols is reduced to a tungsten and molybdenum. The tungsten and molybdenum are reduced and then blue coloration was produced. The blue color has maximum absorption in the region of $760 \mathrm{~nm}$ and it is directly proportional to the total quantity of phenolic compounds originally present. The gallic acid solution of concentration conformed with a regression coefficient $\left(R^{2}\right)=0.991$. The plot has a

Table 3: Total phenolic content of n-hexane, ethyl acetate, and ethanol extracts of Cleome gynandra leaves

\begin{tabular}{llll}
\hline \multirow{2}{*}{ Trials } & \multicolumn{3}{l}{ Total phenolic content of GAE $\mathbf{~ m g} / \mathrm{g}$} \\
\cline { 2 - 4 } & $\begin{array}{l}\text { n-hexane } \\
\text { extract }\end{array}$ & $\begin{array}{l}\text { Ethyl acetate } \\
\text { extract }\end{array}$ & $\begin{array}{l}\text { Ethanolic } \\
\text { extract }\end{array}$ \\
\hline Trial-I & - & 0.016 & 8.56 \\
Trial-II & - & 0.016 & 8.23 \\
Trial-III & - & 0.0083 & 8.4 \\
Mean \pm SEM & - & $0.013 \pm 0.002567$ & $8.39 \pm 0.0952$ \\
\hline
\end{tabular}

GAE: Gallic acid equivalent, SEM: Standard error of mean

Table 4: Total flavonoid content of n-hexane, ethyl acetate, and ethanol extracts of Cleome gynandra leaves

\begin{tabular}{llll}
\hline Trials & \multicolumn{3}{l}{ Total flavonoid content RUE $\mathbf{~ m g} / \mathbf{g}$} \\
\cline { 2 - 4 } & $\begin{array}{l}\mathbf{n} \text {-hexane } \\
\text { extract }\end{array}$ & $\begin{array}{l}\text { Ethyl acetate } \\
\text { extract }\end{array}$ & $\begin{array}{l}\text { Ethanolic } \\
\text { extract }\end{array}$ \\
\hline Trial-I & 10.4 & 20 & 66.8 \\
Trial-II & 10.2 & 19.6 & 66.8 \\
Trial-III & 10.3 & 19.9 & 67.8 \\
Mean \pm SEM & $10.3 \pm 0.057735$ & $19.8 \pm 0.120185$ & $66.76 \pm 0.0333$ \\
\hline
\end{tabular}

RUE: Rutin equivalent, SEM: Standard error of mean

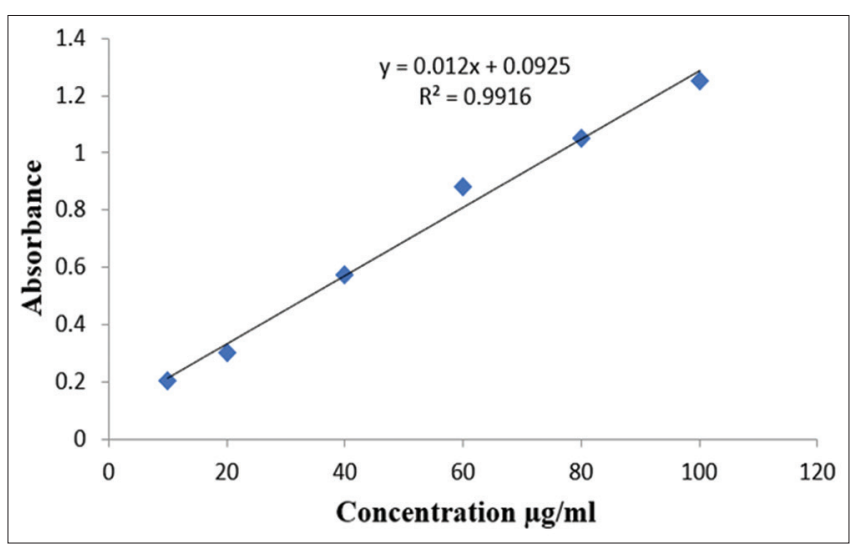

Fig. 2: Standard graph of gallic acid

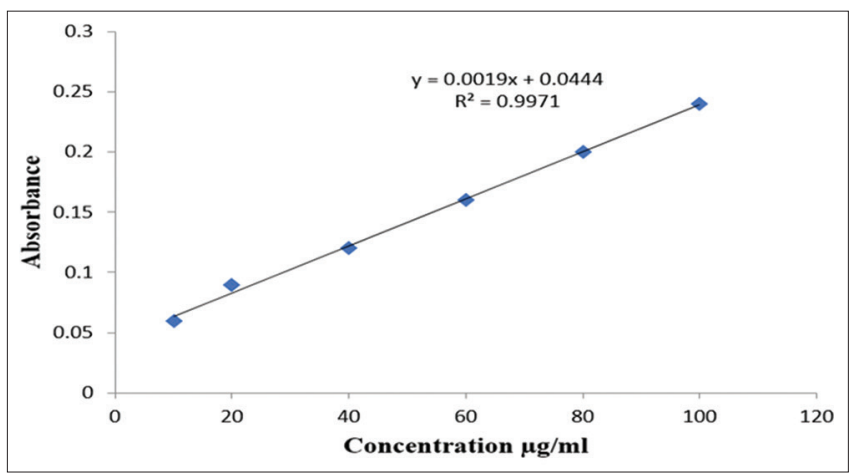

Fig. 3: Standard graph of rutin slope $(\mathrm{m})=0.012$ and intercept $=0.092$. The equation of standard curve is $y=m x+c$ (Fig. 2) and values are shown in Table 3 .

The total flavonoid content of fractions of ethanolic extract was measured using aluminum chloride colorimetric assay using rutin as standard. Aluminum chloride forms acid stable complexes with the flavones and flavonols. In addition, it also forms liable complexes with ortho dihydroxide groups in $\mathrm{A} / \mathrm{B}$ rings of flavonoids. The rutin solution of concentration (100-1000 ppm) conformed to Beer's law at $510 \mathrm{~nm}$ with a regression coefficient $\left(R^{2}\right)=0.997$, the plot has a slope $(\mathrm{m})=0.001$ and intercept $=0.004$. The equation of standard curve is $\mathrm{y}=0.001 \mathrm{x}+0.044$ (Fig. 3) and values are presented in Table 4

Antioxidant activity of different fractions of $C$. gynandra leaf extracts was carried out by DPPH radical scavenging assay and results are shown in Tables 5-7 and Figs. 4-6.

\section{DISCUSSION}

The phytochemical analysis of the ethanolic leaf extract of $C$. gynandra $\mathrm{L}$. revealed the presence of alkaloids, flavonoids, tannins, saponins, cardiac glycosides, phenols, and steroids and absence of terpenoids and anthraquinones. The FTIR spectrum of the ethanolic leaf extract of C. gynandra showed intense bands at 3679.18, 3616.63, 3317.34,

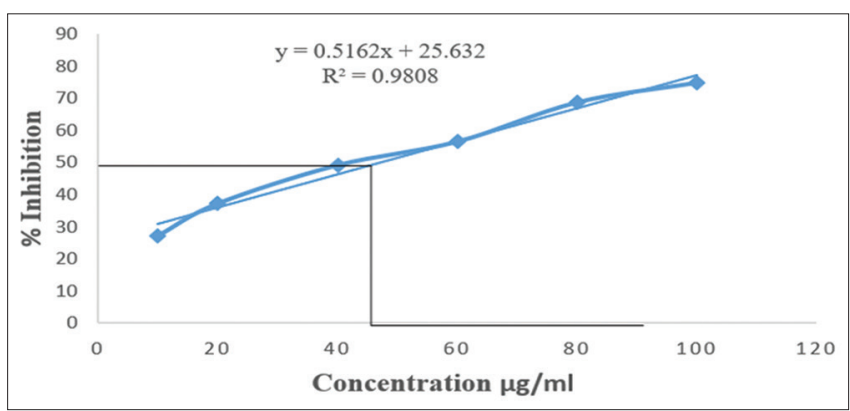

Fig. 4: Effect of the ethanolic leaf extract of Cleome gynandra on 2,2-diphenyl-1-picrylhydrazyl scavenging activity

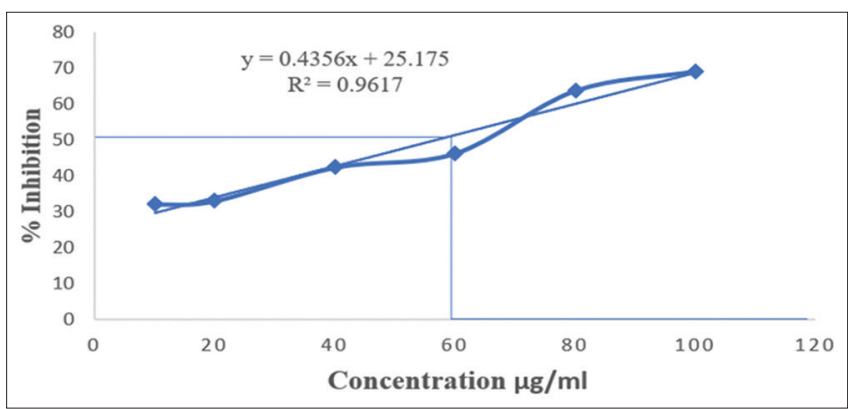

Fig. 5: Effect of the ethyl acetate leaf extract of Cleome gynandra on 2,2-diphenyl-1-picrylhydrazyl scavenging activity

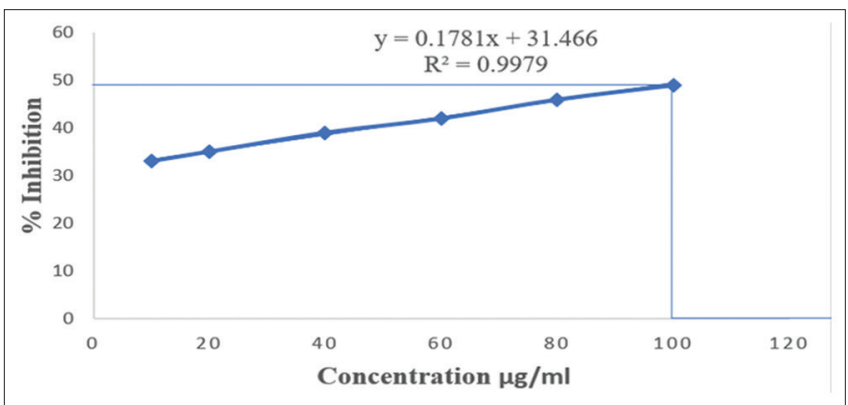

Fig. 6: Effect of the $n$-hexane leaf extract of Cleome gynandra on 2,2-diphenyl-1-picrylhydrazyl scavenging activity 
Table 5: Absorbance and percentage radical scavenging activity values of different concentrations of the ethanolic leaf extract of Cleome gynandra

\begin{tabular}{lll}
\hline Ethanolic extract concentrations $(\boldsymbol{\mu g} / \mathbf{m l})$ & Absorbance & Percentage radical scavenging activity \\
\hline 10 & 0.488 & 27.3 \\
20 & 0.421 & 37.3 \\
40 & 0.341 & 49.2 \\
60 & 0.292 & 56.5 \\
80 & 0.210 & 68.7 \\
100 & 0.169 & 74.8 \\
(Standard) Ascorbic acid & 0.09 & 85.2 \\
\hline
\end{tabular}

Table 6: Absorbance and percentage radical scavenging activity values of different concentrations of the ethyl acetate leaf extract of Cleome gynandra

\begin{tabular}{llll}
\hline Ethyl acetate extract concentrations $(\boldsymbol{\mu g} / \mathbf{m l})$ & Absorbance & Percentage radical scavenging activity & IC $_{50}(\boldsymbol{\mu g} / \mathbf{m l})$ \\
\hline 10 & 0.182 & 32 \\
20 & 0.178 & 33 \\
40 & 0.155 & 42.3 \\
60 & 0.143 & 46.2 \\
80 & 0.099 & 63.6 \\
100 & 0.082 & 69 \\
(Standard) Ascorbic acid & 0.09 & 85.2 \\
\hline
\end{tabular}

Table 7: Absorbance and percentage radical scavenging activity values of different concentrations of the n-hexane leaf extract of Cleome gynandra

\begin{tabular}{lll}
\hline $\mathbf{n}$-hexane extract concentrations $(\boldsymbol{\mu g} / \mathbf{m l})$ & Absorbance & Percentage radical scavenging activity $^{\text {IC }_{\mathbf{5 0}}(\boldsymbol{\mu} \mathbf{g} / \mathbf{m l})}$ \\
\hline 10 & 0.370 & 33 \\
20 & 0.362 & 35 \\
40 & 0.339 & 39 \\
60 & 0.321 & 42 \\
80 & 0.302 & 46 \\
100 & 0.282 & 49 \\
(Standard) Ascorbic acid & 0.09 & 85.2 \\
\hline
\end{tabular}

2943.67,1634.01, 1360.20, 1036.71, and $778.04 \mathrm{~cm}^{-1}$ corresponding to $\mathrm{N}-\mathrm{H}_{2}, \mathrm{O}-\mathrm{H}$ stretch, aliphatic $\mathrm{C}-\mathrm{H}$ stretch, $\mathrm{C}=\mathrm{O}$, C-H benzene, C-O stretch, and C-Cl. This confirms the presence of functional groups in C. gynandra such as amines, amides, hydroxyl, carbonyl, benzene, ether, and halogen. Strong absorption band observed around 3679.18-3616.63 $\mathrm{cm}^{-1}$ indicates the presence of amines and amides. Absorption band observed at $3317.34 \mathrm{~cm}^{-1}$ shows the presence of polymeric hydroxyl derivatives. The vibration of $\mathrm{N}-\mathrm{H}$ band indicates the presence of primary amines. Strong absorption band observed near $2943.67 \mathrm{~cm}^{-1}$ shows aliphatic C-H symmetric stretching of methylene group. Strong absorption band observed near 1634-1036 $\mathrm{cm}^{-1}$ was due to the presence of chelated $\mathrm{C}=\mathrm{O}, \mathrm{C}=\mathrm{C}$, and $\mathrm{C}-\mathrm{O}$ stretching. Absorption band observed at $778.04 \mathrm{~cm}^{-1}$ shows the presence of halogen. These functional groups, in turn, indicate the presence of flavonoids, saponins, tannins, alkaloids, glycosides, and polyphenols; thus, this spectral analysis is correlated with phytochemical evaluation of $C$. gynandra leaf extract. The total flavonoid content of n-hexane, ethyl acetate, and ethanolic extracts values was found to be $10.3 \pm 0.057735,19.8 \pm 0.120185$, and $66.76 \pm 0.033$ rutin equivalent $\mathrm{mg} / \mathrm{g}$. Furthermore, total phenolic content was not found in n-hexane extract and ethyl acetate extract was found to be $0.013 \pm 0.002567$ and ethanol extract was found to be $8.39 \pm 0.0952 \mathrm{GAE} \mathrm{mg} / \mathrm{g}$. Antioxidant activity was carried out using DPPH radical scavenging assay, the $\mathrm{IC}_{50}$ values of n-hexane, ethyl acetate, and ethanol were found to be $100 \mu \mathrm{g} / \mathrm{ml}$ (almost nil activity), $60 \mu \mathrm{g} / \mathrm{ml}$, and $44 \mu \mathrm{g} / \mathrm{ml}$. Based on the $\mathrm{IC}_{50}$ values of the extracts, the ethanolic leaf extract was showed more radical scavenging activity as compared to ethyl acetate extract. In this study, flavonoid contents were directly related with the antioxidant activity in the DPPH. It is known that flavonoids have the strongest radical-scavenging power among all other natural phenolic compounds.

\section{CONCLUSION}

The ethanolic leaf extract of C. gynandra was subjected to phytochemical and FTIR analysis. Almost all the functional groups and chemical constituents and total phenolic, total flavonoid contents present in n-hexane, ethyl acetate, and ethanolic extracts of $C$. gynandra leaves were identified using analytical techniques. These compounds are responsible for several biological functions in the human body and they have great pharmaceutical application. The antioxidant activity showed by ethanolic leaf extract of $C$. gynandra was more due to the presence of phytochemical principles. Therefore, further works have been performed on the isolation and identification of the antioxidant components present in ethanolic leaf extract and its fractions of C. gynandra.

\section{ACKNOWLEDGMENTS}

The authors are grateful thanks to the Department of Science and Technology-Science and Engineering Research Board (DST-SERB) for financial support.

\section{AUTHORS' CONTRIBUTIONS}

All authors contribute equally in data collection, experimental interpretation, statistical analysis, literature review, and manuscript preparation.

\section{COMPETING INTERESTS}

All the authors declared no conflicts of interest.

\section{REFERENCES}

1. Rajaselvam J, Rose MR. In vitro antimicrobial activity and phytochemical analysis of Cleome gynandra Linn leaf extracts against human pathogens. Int J Res Appl Sci Eng Technol 2016;4:793-6.

2. Magajyarkarasi A, Muhammad Ilyas. Phytochemical screening and fluorescence analysis of Cleome gynandra L leaves. Int J Curr Res 
Biosci Plant Biol 2015;2:58-65.

3. Prakash NK, Ranjithkumar M, Sripriya N, Lakshmi RP, Deepa S, Bhuvaneswari S. Antioxidant, free radical scavenging activity and GCMS studies on Pedilanthus tithymaloides (L.) Poit. Int J Pharm Pharm Sci 2014;6:284-7.

4. Mishra SS, Moharana SK, Dash MR. Review on Cleome gynandra. Int J Res Pharm Chem 2011;1:68-89.

5. Annkangai M, Felister N, Jane A, Damaris O. Heritability analysis and phenotypic characterization of spider plant (Cleome gynandra L.) for yield. Adv Agric 2018;2018:1-11.

6. Ranjitha J, Bakiyalakshmi K, Anand M, Sudha PN. Phytochemical investigation of n-hexane extract of leaves of Cleome gynandra. Asian J Chem 2009;21:3455-8.

7. Shanmuganathan T, Karthikeyan AV. Free radical scavenging activity of aqueous and ethanolic extract of wild and L-Arginine treated Cleome gynandra L. Int J Pharm Sci Res 2014;5:346-9.

8. Lokesha R. The African spider plant (Gynandropsis pentaphylla-DC. Syn. Cleome gynandra Linn.) (Capparaceae): Phytochemistry, pharmacological and biotechnological properties a review. Int J Pharm Chin Med 2018:2:1-14.

9. Mallikarjuna G, Shireesha T, Sree VS, Priyadarshini MS, Naik MR, Charitha Y. Evaluation of hypolipidemic activity of Cleome gynandra $\mathrm{L}$. Against dexamethasone induced hyperlipidemia in rats. Int J Pharm Sci Rev Res 2018;50:47-52.

10. Ashree CL, Kumar JK, Prasad AG, Zarei M, Gopal S. FTIR spectroscopic studies on Cleome gynandra comparative analysis of functional group before and after extraction. Rom J Biophys 2013;3:137-43.

11. Kumar RA, Ramaswamy M. Phytochemical screening by FTIR spectroscopic analysis of leaf extracts of selected Indian medicinal plants. Int J Curr Microbiol Appl Sci 2014;3:395-406.

12. Wulandri L, Retnaningtyas Y, Nuri, Lukman H. Analysis of flavonoid in medicinal plant extract using infrared spectroscopy and chemometrics. J Anal Methods Chem 2016;2016:1-6.

13. Sujatha S, Sekar T. Free-radical scavenging activity leaf extract of Lisea laevigata gamble. Int J Pharm Pharm Sci 2019;11:96-103.

14. Islam MN, Kabir MS, Kader SM, Hasan M, Samrat EK, Habib IB, et al. Total phenolic and total flavonoid and antioxidant potential of methanolic extract of Boehmeria platyphylla D don leaves. World J Pharm Res 2016;5:334-44.

15. Linda I. Sowunmi, Anthony J. Afolayan. Phytochemical constituents and antioxidant properties of acetone extract of Cleome gynandra L. Growing in the Eastern cape, South Africa. Afr J Tradit Complement Altern Med 2015;12:1-8.

16. Murugan M, Mohan VR. Phytochemical, FT-IR and antibacterial activity of whole plant extract of Aerva lanata (L.) juss ex schult. J Med Plants Stud 2014;2:51-7.

17. Marinova D, Ribarova F, Atanassova M. Total phenolics and total flavonoids in Bulgarian fruits and vegetables. J Univer Chem Technol Metall 2005;40:255-60.

18. Blois MS. Antioxidant determinations by the use of a stable free radical. Nature 1958;181:1199-200. 